\title{
Uterine Corpus Leiomyosarcoma and Endometrial Stromal Sarcoma pT1 TNM Finding v8
}

National Cancer Institute

\section{Source}

National Cancer Institute. Uterine Corpus Leiomyosarcoma and Endometrial Stromal

Sarcoma pT1 TNM Finding v8. NCI Thesaurus. Code C139827.

Uterine corpus leiomyosarcoma or endometrial stromal sarcoma with tumor limited to

the uterus. (from AJCC 8th Ed.) 